\title{
Single central nervous system lesions can simulate multiple sclerosis
}

\author{
D.G. Grosset, D.M. Hadley and I. Bone
}

Institute of Neurological Sciences, Department of Neurology, Institute of Neurological Sciences, Southern General Hospital, Glasgow G51 4TF, UK.

\begin{abstract}
Summary: Three cases are reported in which an initial misdiagnosis of multiple sclerosis was made. In each of these a single central nervous system lesion with space occupying effect was present. These lesions caused confusion because multiple closely running neurological tracts were affected, and there was relapse and remission in the neurological signs and symptoms produced. We conclude that such cases need careful assessment to determine whether a single structural lesion could explain the presentation. Early imaging may show remediable lesions or prevent unnecessary steroid therapy.
\end{abstract}

\section{Introduction}

Relapsing and remitting neurological symptoms and signs should be carefully assessed to determine whether an underlying single structural lesion could be responsible. We report three cases in which delay in diagnosis was caused by an initial incorrect label of multiple sclerosis.

\section{Case reports}

\section{Case 1}

A 17 year old girl had episodic dragging of the left leg and dull aching limb pains over a period of 2 years. There had been transient left limb weakness 6 years previously. Initial assessment found only bilateral ankle clonus. Multiple sclerosis was presumed but further investigation not instituted. During the next two months, progressive difficulty in walking followed due to stiffness of both legs. There was a single episode of paraesthesia of one hand. Precipitancy of micturition developed. The limb pains had by now remitted. She was referred for neurological assessment. This showed spastic paraparesis with dorsal column sensory loss in the legs and an area of hyperaesthesia in the right tenth thoracic dermatome. Poor heel-shin coordination was elicited, due to proprioceptive loss

Correspondence: D.G. Grosset, M.R.C.P.

Accepted: 9 March 1989 and weakness. Plain spinal X-rays showed considerable widening of the lower cervical and upper thoracic canal with retained bony cortication, indicating a chronic expanding lesion. Cervical myelography showed a large exophytic intramedullary tumour extending downwards from the level of the sixth cervical vertebra (Figure 1). The cerebrospinal fluid had a high IgG:albumin index at 0.94, reference range $0.26-0.66$, but was otherwise normal with no oligoclonal bands. At laminectomy, a huge intradural lipomatous swelling extended from the sixth cervical to the third thoracic vertebra. It was only partially resectable as there was no plane of cleavage with the cord. Microscopically it was a lipoma. There was slow return to almost normal walking, but only partial proprioceptive recovery, at review 3 years later.

\section{Case 2}

A 25 year old man had transient diplopia followed by numbness of the face and left palm. There were no abnormal physical signs. He deteriorated while on intramuscular ACTH therapy for presumed multiple sclerosis. Neurological referral was made. He had developed a small right pupil, a right 6th nerve palsy, internuclear ophthalmoplegia, vertical nystagmus, mild right facial weakness, reduced perioral and left facial sensation, and slight dysarthria, with decreased sensation to all modalities in the left arm and leg, and a left extensor plantar. Computed tomography and

(C) The Fellowship of Postgraduate Medicine, 1989 


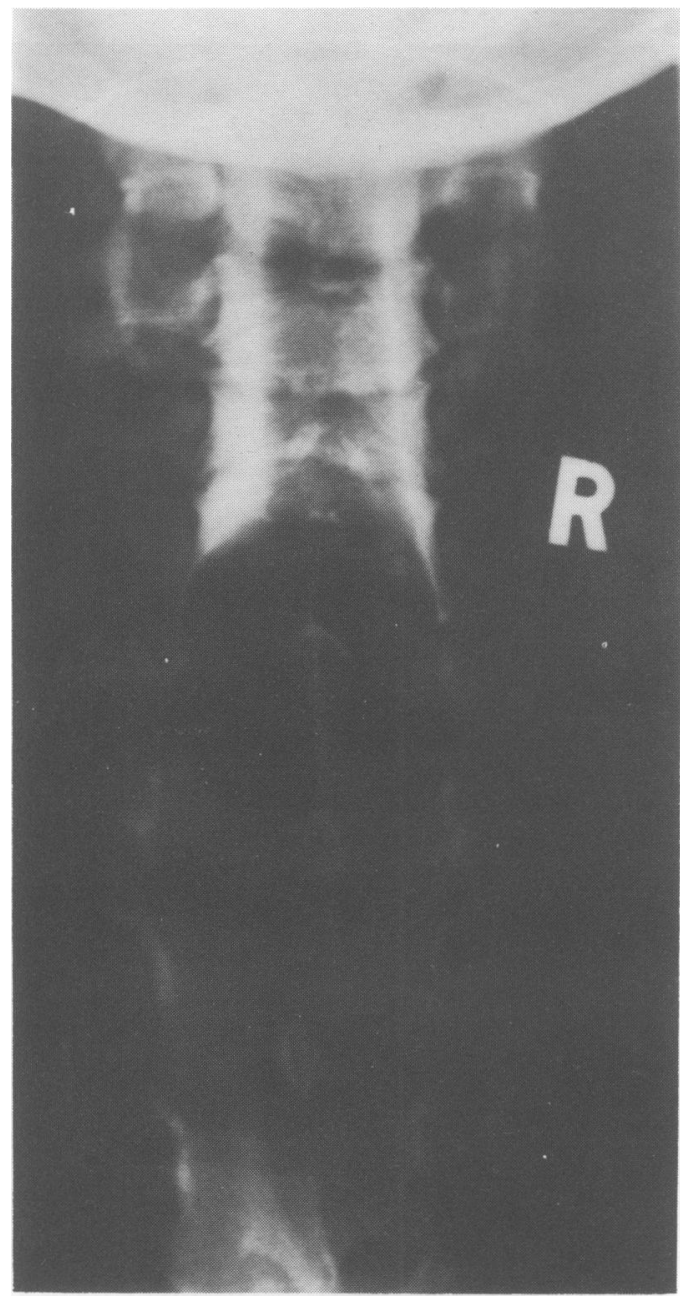

Figure 1 Myelogram in Case 1, showing widened cervicothoracic canal with contrast outlining a chronic expanding exophytic intradural lesion, at operation found to be a lipoma.

magnetic resonance imaging showed a large haematoma in the right pons, compressing and displacing the 4th ventricle (Figure 2). There was no subarachnoid blood. Bilateral vertebral angiography was normal. Repeat computed tomography and magnetic resonance scans at one month, and magnetic resonance scans at three months, showed slow resolution of the haematoma. Visual evoked responses were normal. Cerebrospinal fluid was normal with no oligoclonal bands. The patient was managed conservatively during a total hospital admission of 60 days. Three months later there was no detectable neurological deficit.

\section{Case 3}

A 48 year old man developed slurred speech, emotional lability, and transient right leg weakness. Six years previously an episode of abrupt unconsciousness followed a hot bath. Five years previously he suffered two tonic clonic seizures. Three years previously a

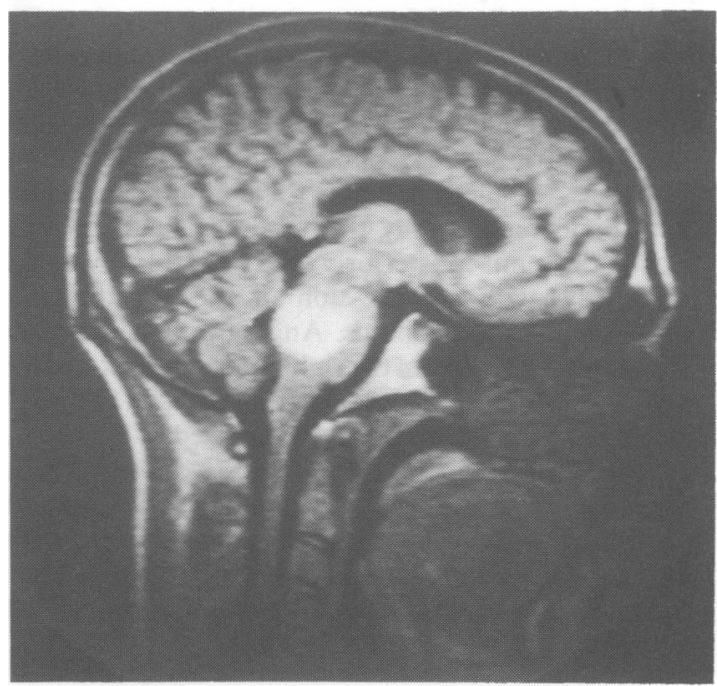

b

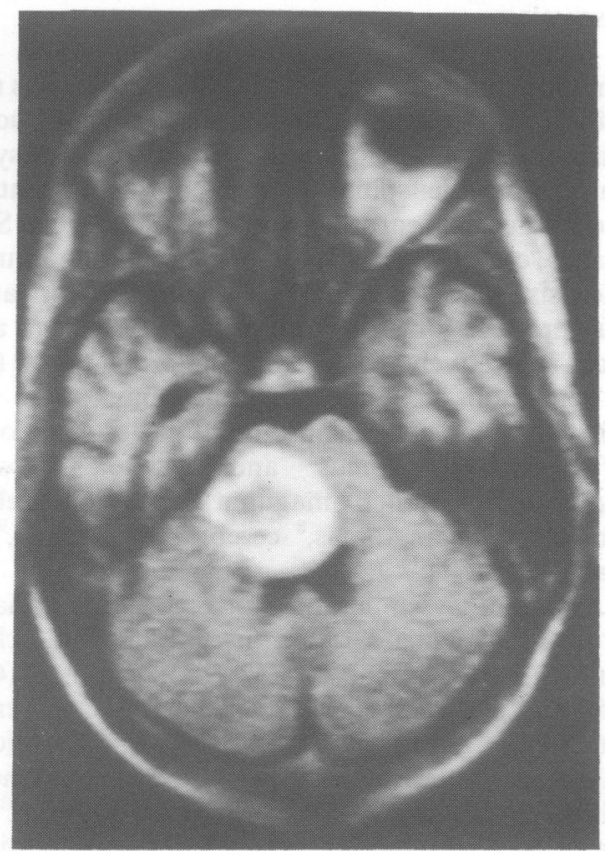

Figure 2 (a) Sagittal (SE 500/40) and (b) axial (IR $2000 / 400 / 40$ ) $M R I$ in Case 2, showing a right pontine haematoma. 
during two weeks of unsteady walking, he had slurred speech for 3 hours. In the previous 10 months there was intermittent right sided ptosis with pupillary dilatation, choking with food, and slurred speech. Examination elicited hyperactive reflexes with a positive jaw jerk, and the optic discs had possible temporal pallor. Cerebrospinal fluid examination for presumed multiple sclerosis was normal. One month later he was referred for neurological assessment. The reflex changes noted previously were confirmed. A dilated unreactive right pupil, a slight right ptosis, and right sided tongue wasting had now developed. There was dysarthria and dysphonia, and a mild right limb weakness. Magnetic resonance examination showed a $3 \mathrm{~cm}$ diameter partially thrombosed aneurysm displacing the pons posteriorly and the third ventricle superiorly, with compression of the aqueduct and consequent hydrocephalus. Angiography showed the aneurysm to arise from the right internal carotid artery near the posterior communicating artery (Figure 3). The aneurysm was clipped and excised.

Postoperatively a left hemiparesis due to a small capsular infarction (computer tomography confirmed) was attributed to temporary clipping of the internal carotid artery. At two years, severe left arm weakness remained, but swallowing and speech had improved.

\section{Discussion}

An initial misdiagnosis of multiple sclerosis was made elsewhere in these cases, and in each a single structural space-occupying lesion in the central nervous system was responsible: spinal lipoma, pontine haematoma, and intracranial carotid aneurysm respectively. Single lesions can remit and relapse simulating multiple sclerosis. ${ }^{1,2}$ Slower expanding lesions (Cases 1 and 3) may produce longer symptom-free intervals ( 4 and 2 years respectively) but in an acute presentation (Case 2) remission of some symptoms may occur while others develop. The relapse-remit pattern also occurs in brainstem gliomas ${ }^{3}$ and angiomas, ${ }^{4,5}$ spinal angiomas, ${ }^{6}$ foramen magnum lesions, ${ }^{7}$ cerebellar tumours, ${ }^{2}$ meningiomas, ${ }^{8}$ cerebral lymphoma, ${ }^{9}$ and arachnoid cysts. ${ }^{10}$

Apparent dissemination, simulating demyelination, is produced when a lesion disrupts multiple closely running tracts. Spinal cord (Case 1), brainstem (Cases 2 and 3 ), and cerebellar and optic tract involvement, are emphasized in this regard. ${ }^{11}$ Temporal optic disc pallor (suspected initially in Case 2) should not be relied upon as sole evidence of eye involvement ${ }^{11}$ and hence of dissemination; evoked response testing is helpful in these circumstances. ${ }^{12}$

Diagnostic criteria for multiple sclerosis ${ }^{13}$ classify patients into clinically and laboratory-supported a

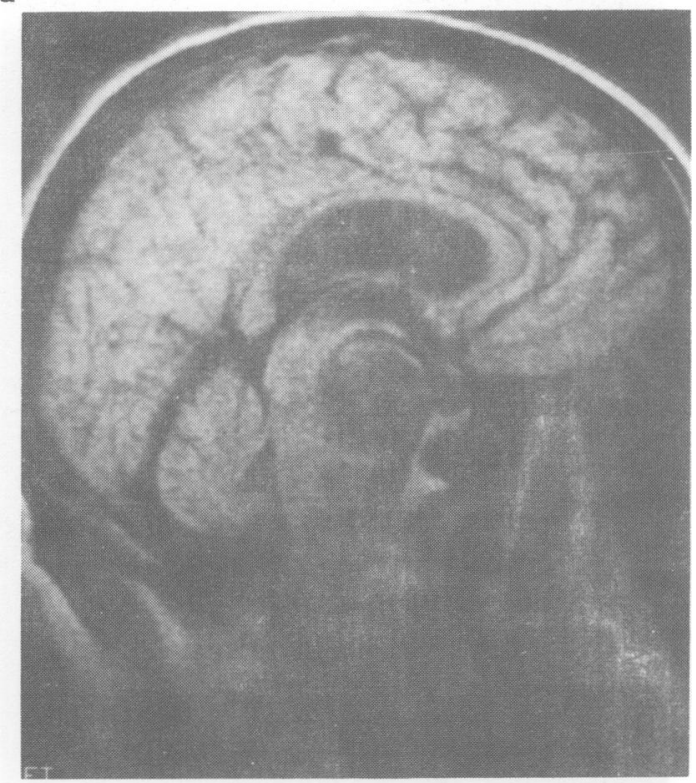

b

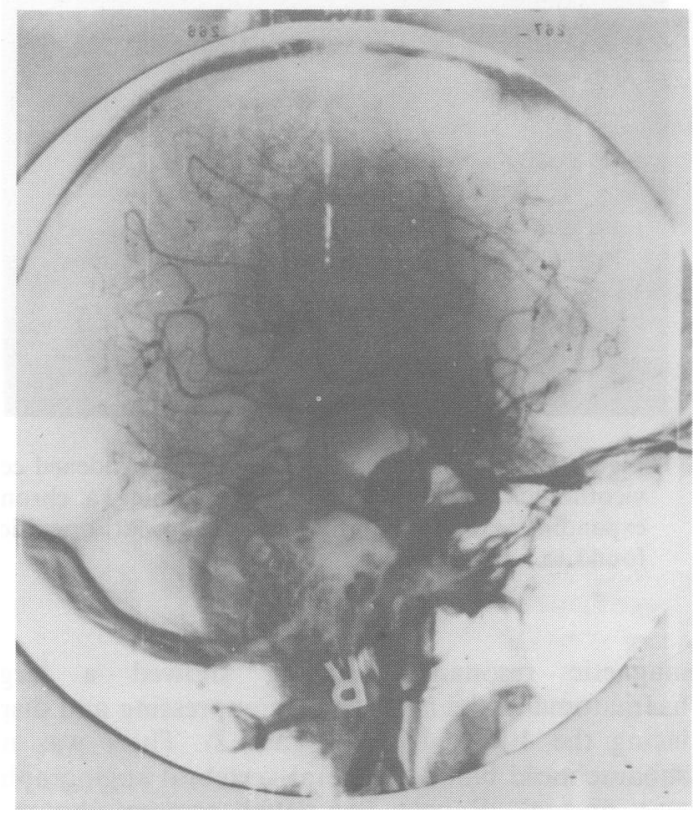

Figure 3 (a) Sagittal (SE 700/32) MRI and (b) carotid angiogram in Case 3 with a right internal carotid artery aneurysm impinging on and displacing the anterior pons.

definite, and probable, groups on the basis of attacks of neurological dysfunction, physical signs, and laboratory investigations. Application of such criteria, 
mandatory in clinical research, also provides a useful framework for individual case diagnosis. ${ }^{14}$ None of the illustrated cases fulfil the Poser criteria; the definition of separate symptoms and signs, ${ }^{11}$ which must never be explicable by a single lesion, is of paramount importance here. Criteria for multiple sclerosis can be fulfilled when multiple sclerosis is not the correct diagnosis, however. ${ }^{13}$ Selection of patients requiring early investigation can be helped by 'negative' criteria ${ }^{1}$ casting doubt on the diagnosis, one or more of absence of eye signs, remissions, sensory findings, or bladder involvement. Normal visual evoked responses and/or spinal fluid analysis (Case 3) will heighten suspicion of an alternative diagnosis, ${ }^{4}$ but the false negative rate for both investigations is high in early multiple sclerosis. ${ }^{15}$ In Case 1 , however, the first episode was 4 years prior to presentation, and inves-

\section{Referencess}

1. Rudick, R.A., Schiffer, R.B., Schwetz, K. \& Herndon, R.M. Multiple sclerosis: the problem of misdiagnosis. Arch Neurol 1986, 43: 578-583.

2. Matthews, W.B. Differential diagnosis. In: Matthews, W.B. (ed.) McAlpine's Multiple Sclerosis. Churchill Livingstone, London, 1985, pp. 146-166.

3. Britt, R.H., Connor, S.W. \& Enzmann, D.R. Occult arteriovenous malformation of the brainstem simulating multiple sclerosis. Neurology 1981, 31: 901-903.

4. Stahl, S.M., Johnson, K.P. \& Malamud, N. The clinical and pathological spectrum of brain-stem vascular malformations. Long-term course simulates multiple sclerosis. Arch Neurol 1980, 37: 25-29.

5. Sadeh, M., Shaked, I., Rappaport, Z.H. \& Tadmor, R. Surgical extirpation of a venous angioma of the medulla oblongata simulating multiple sclerosis. Surg Neurol 1982, 17: 334-335.

6. Aminoff, M.J. \& Logue, V. Clinical features of spinal vascular malformations. Brain 1974, 97: 197-210.

7. Cohen, L. \& Macrae, D. Tumours in the region of the foramen magnum. $J$ Neurosurg 1962, 19: 462-469.

8. Bickerstaff, E.R., Small, J.M. \& Guest, I.A. The relapsing course of certain meningiomas in relation to pregnancy and menstruation. J Neurol Neurosurg Psychiatry 1958, 21: 89-91. tigative delay was due to clinical well-being. Treatment without investigation (Case 2) will confuse if an alternative cause is steroid-responsive. ${ }^{9}$

In conclusion a relapsing and remitting neurological illness in which clearly disseminated involvement is not present may be due to a single structural space-occupying lesion. Early investigation in such circumstances can lead to identification of remediable conditions.

\section{Acknowledgements}

We would like to thank our neurosurgical colleagues. The Magnetic Resonance Imaging unit is funded by grants from the Medical Research Council and Scottish Hospitals Endowment Research Trust.

9. Ruff, R.L., Petito, C.K. \& Rawlinson, D.G. Primary cerebral lymphoma mimicking multiple sclerosis. Arch Neurol 1979, 36: 598

10. Lehman, R.A.W. \& Fieger, H.G. Arachnoid cyst producing recurrent neurological disturbances. Surg Neurol 1978, 10: 134-136.

11. Kurtze, J.F. Clinical manifestations of multiple sclerosis. In: Vinken, P.J. and Bruyn, G.W. (eds) Handbook of Clinical Neurology, volume 9. North Holland Publishing Company, Amsterdam, New York, 1970, pp. 161-216.

12. McDonald, W.I. The role of evoked potentials in the diagnosis of multiple sclerosis. In: Bauer, H.J., Poser, S., Ritter, G. (eds) Progress in Multiple Sclerosis Research. Springer-Verlag, New York, 1980, pp. 564-568.

13. Poser, C.M., Pary, D., Scheinberg, L. et al. New diagnostic criteria for multiple sclerosis: guidelines for research protocols. Ann Neurol 1983, 13: 227-231.

14. Ebers, G.C. Multiple sclerosis and other demyelinating disease. In: Asbury, A.K., McKhann, G.M., McDonald, W.I. (eds) Diseases of the Nervous System. Heinemann, London, 1986, pp. 1268-1281.

15. Matthews, W.B. Laboratory diagnosis. In: Matthews, W.B. (ed.) McAlpine's Multiple Sclerosis. Churchill Livingstone, London, 1985, pp. 167-209. 